\title{
Addition of GM-CSF to trastuzumab stabilises disease in trastuzumab-resistant HER2 + metastatic breast cancer patients
}

\author{
YC Cheng ${ }^{1,2}, V_{\text {Valero }}^{3}$, ML Davis $^{3}$, MC Green $^{3}$, AM Gonzalez-Angulo $^{3}$, RL Theriault ${ }^{3}$, JL Murray ${ }^{3}$, \\ GN Hortobagyi ${ }^{3}$ and NT Ueno ${ }^{*, 2,3}$
}

'Division of Neoplastic Diseases and Related Disorders, Department of Medicine, Medical College of Wisconsin, Milwaukee, WI, USA; ${ }^{2}$ Department of Stem Cell Transplantation and Cellular Therapy, The University of Texas MD Anderson Cancer Center, 1515 Holcombe Boulevard, Unit 448, Houston, TX, USA; ${ }^{3}$ Breast Cancer Translational Research Laboratory, Department of Breast Medical Oncology, The University of Texas MD Anderson Cancer Center, 1515 Holcombe Boulevard, Unit 1354, Houston, TX 77030, USA

\begin{abstract}
BACKGROUND: One of the proposed mechanisms of trastuzumab-induced regression of human epidermal growth factor receptor 2-positive $(\mathrm{HER} 2+)$ tumours includes facilitation of antibody-dependent cell-mediated cytotoxicity (ADCC). Granulocytemacrophage colony-stimulating factor (GM-CSF) mediates ADCC. We presented our pilot study of adding GM-CSF to trastuzumab in patients with trastuzumab-resistant HER2 + metastatic breast cancer.

METHODS: Patients with HER2 + metastatic breast cancer that progressed after trastuzumab + / chemotherapy were continued on trastuzumab $2 \mathrm{mg} \mathrm{kg}^{-1}$ intravenous weekly and GM-CSF $250 \mu \mathrm{g} \mathrm{m}^{-2}$ subcutaneous daily. Patients were assessed for response every 8 weeks. Treatment was continued until disease progression or intolerable toxicity.

RESULTS: Seventeen patients were evaluable (median age 48 years, range 27-75 years). The median number of metastatic sites was 2 (range I-3); the most common site was the liver $(n=10)$. The median number of prior regimens for metastatic disease was 2 (range I-5). No objective disease response was observed, but five patients (29\%) had stable disease for a median duration of 15.8 (range 10-53.9) weeks. The most common adverse event was rash at the injection site. No grade 4 or irreversible adverse event was seen.

CONCLUSION: The addition of GM-CSF to trastuzumab alone had a modest clinical benefit and acceptable safety profile in heavily pretreated patients with trastuzumab-resistant HER2 + metastatic breast cancer.

British Journal of Cancer (2010) 103, I33I-1334. doi:I0.1038/sj.bjc.66059I8 www.bjcancer.com

Published online 28 September 2010

(c) 2010 Cancer Research UK
\end{abstract}

Keywords: granulocyte-macrophage colony-stimulating factor; HER2; metastatic breast cancer; trastuzumab

Metastatic breast cancer is generally considered incurable by standard chemotherapy. Nevertheless, it is a chemosensitive disease. Among patients treated with chemotherapy, median survival is 24 months, and $2-5 \%$ patients have disease-free survival longer than 5 years. Multiple prognostic and predictive factors determine the course of the disease and the response to systemic treatment. One of these factors is expression of the human epidermal growth factor receptor 2 (HER2), which is overexpressed in $\sim 20 \%$ of breast cancers (Slamon et al, 2001).

The HER 2 oncogene is a member of the HER family of tyrosine kinase receptors. Amplification of HER2 results in overexpression of the HER2 receptor, which correlates with several negative prognostic variables, including oestrogen receptor-negative status, high S-phase fraction, positive nodal status, mutated $p 53$, and high nuclear grade (Sjögren et al, 1998). Overexpression of the HER2 receptor in turn results in relative resistance to endocrine therapy (Atalay et al, 2003) and is correlated with an aggressive form of breast cancer and significantly shorter disease-free and overall survival (Press et al, 1993; Seshadri et al, 1993; Ravdin

*Correspondence: Dr NT Ueno; E-mail: nueno@mdanderson.org Received 18 May 2010; revised 2 August 2010; accepted 25 August 20I0; published online 28 September 2010 and Chamness, 1995; Cobleigh et al, 1999; Slamon et al, 1987). As overexpression of HER2 receptor is such an important prognostic and predictive factor (Pietras et al, 1995), targeting this receptor with tumour-specific passive and active immunotherapeutic treatments is a rational strategy.

The humanised monoclonal antibody trastuzumab was developed as a therapy targeted against HER2 receptor. In patients with HER2-positive (HER2 + ) metastatic breast cancer, response rates to trastuzumab monotherapy range from 12 to $34 \%$, median duration of response is 9 months (Cobleigh et al, 1999; Nahta et al, 2004). Concomitant trastuzumab and chemotherapy are synergistic and have resulted in better response rates, time to disease progression, and overall survival than chemotherapy alone or trastuzumab monotherapy. Therefore, concomitant trastuzumab and chemotherapy is considered a standard of care in HER2 + metastatic breast cancer (Seidman et al, 2001; Slamon et al, 2001; Esteva et al, 2002; Stein et al, 2004; Marty et al, 2005).

Although the mechanisms by which trastuzumab induces regression of HER $2+$ tumours are not known definitively, proposed mechanisms include potentiation of chemotherapy (Pegram et al, 1999), inhibition of tumour cell proliferation (Baselga et al, 1998; Sliwkowski et al, 1999), and facilitation of immune function through antibody-dependent cell-mediated cytotoxicity (ADCC) (Lewis et al, 1993; Sliwkowski et al, 1999; 
Repka et al, 2003). Thus, ADCC appears to be one of the most important immune effector functions. Cytokines such as granulocyte-macrophage colony-stimulating factor (GM-CSF) may augment ADCC by direct activation of immune cells or by enhancement of tumour-associated antigens on tumour cells (Sondel and Hank, 2001).

We hypothesised that adding GM-CSF to trastuzumab would overcome trastuzumab resistance via enhancing ADCC. We hereby present the results of our pilot study assessing the feasibility, safety profile, and efficacy of adding GM-CSF to trastuzumab in women with trastuzumab-resistant metastatic breast cancer.

\section{PATIENTS AND METHODS}

\section{Trial design}

All patients provided written informed consent prior to participating in the pilot study, and the study was reviewed and approved by the Institutional Review Board at The University of Texas MD Anderson Cancer Center. Eligible patients were women with metastatic breast cancer who had HER2-overexpressing disease (HER $23+$ by immunohistochemical staining or amplification by fluorescence in situ hybridisation) that was progressing after treatment with at least one cycle of trastuzumab with or without chemotherapy. Patients were required to have an Eastern Cooperative Oncology Group performance status score of 0 or 1, an adequate haematological profile, and adequate liver, kidney, and heart function. Patients also were required to have measurable metastatic disease. Patients with only bone disease, only leptomeningeal disease, or only malignant pleural effusion were not eligible.

\section{Treatment}

Trastuzumab was intravenously given as follows: a $4 \mathrm{mg} \mathrm{kg}^{-1}$ loading dose followed by $2 \mathrm{mg} \mathrm{kg}^{-1}$ every week for 4 weeks (one cycle). A loading dose was not necessary if patients received trastuzumab within 2 weeks before the start of study treatment. Subcutaneous GM-CSF was given at $250 \mu \mathrm{g} \mathrm{m}^{-2}$ daily until the absolute neutrophil count was $>10000 \mathrm{~mm}^{-3}$, then was given every other day to maintain the absolute neutrophil count below $10000 \mathrm{~mm}^{-3}$. When GM-CSF and trastuzumab were given on the same day, GM-CSF was given before trastuzumab infusion. Patients underwent restaging every 8 weeks (two cycles). Granulocyte-macrophage colony-stimulating factor and trastuzumab were continued until disease progression or intolerable toxic effects. The primary end points of the trial were tumour response (including stable disease) and time to progression. Treatmentrelated toxicity was assessed according to the National Cancer Institute Common Toxicity Criteria version 2.0. Tumour response was assessed according to the Response Evaluation Criteria in Solid Tumours system.

\section{Statistical consideration}

A maximum of 18 patients will be entered in the study. A $15 \%$ (three patients) improved tumour response (including stable disease) rate in this patient population would provide an impetus towards further investigation of this treatment, including measurement of ADCC.

\section{RESULTS}

Eighteen patients with progressive HER2 + metastatic breast cancer were eligible, and 17 were evaluable (median age 48 years, range 27-75 years) (Table 1). One patient did not complete the first cycle because of a protocol violation. Among the 17 evaluable
Table I Patient characteristics ${ }^{\mathrm{a}}$

\begin{tabular}{|c|c|}
\hline \multicolumn{2}{|l|}{ Number of patients } \\
\hline Total & 18 \\
\hline Evaluable & 17 \\
\hline Age in years, median (range) & $48(27-75)$ \\
\hline \multicolumn{2}{|l|}{ Initial disease stage } \\
\hline । & । \\
\hline$\|$ & 5 \\
\hline III & 6 \\
\hline IV & 5 \\
\hline \multicolumn{2}{|l|}{ Hormone receptor status } \\
\hline Positive & 9 \\
\hline Negative & 8 \\
\hline HER2 receptor positive & 18 \\
\hline Neoadjuvant chemotherapy & 6 \\
\hline Anthracycline-containing regimen only & 4 \\
\hline Anthracycline- and taxane-containing regimen & 2 \\
\hline Adjuvant chemotherapy & 9 \\
\hline Anthracycline-containing regimen only & 2 \\
\hline Anthracycline- and taxane-containing regimen & 3 \\
\hline Taxane-containing regimen only & 4 \\
\hline Adjuvant radiation therapy & 5 \\
\hline Adjuvant hormone therapy & 3 \\
\hline Number of systemic regimens after metastasis, median (range) & $2(2-8)$ \\
\hline $\begin{array}{l}\text { Number of trastuzumab-containing regimens after metastasis, } \\
\text { median (range) }\end{array}$ & $2(1-5)$ \\
\hline Number of sites of metastasis, median (range) & $2(1-3)$ \\
\hline \multicolumn{2}{|l|}{ Sites of metastasis } \\
\hline Liver & 10 \\
\hline Bone & 8 \\
\hline Lymph nodes & 6 \\
\hline Lung & 5 \\
\hline Chest wall & 2 \\
\hline Brain & । \\
\hline Peritoneum & I \\
\hline
\end{tabular}

${ }^{a}$ Values are numbers of patients unless otherwise specified.

patients, 9 had hormone receptor-positive disease. The median number of sites of metastasis was 2 (range $1-3$ ). The most common site of metastasis was the liver $(n=10)$. The median number of trastuzumab-containing regimens for metastatic disease was 2 (range 1-5). One patient developed rapidly progressive disease 2 weeks after the start of study therapy and died soon after. Sixteen patients received treatment for at least 8 weeks (two cycles) until disease progression. No disease response was observed, but five patients $(29 \%)$ had stable disease more than 8 weeks. The median duration was 15.8 weeks (range 10-53.9 weeks). Three of the five patients had hormone receptor-negative disease and four of them had visceral organ involvement. Thirteen patients had grade 1 adverse events; six patients had grade 2 adverse events; and two patients had grade 3 adverse events (fatigue, muscle aches, and paraesthesia). The most common adverse events, in decreasing order of frequency, were rash at the GM-CSF injection site, skin rash, fatigue, and muscle aches (Table 2). No grade 4 or irreversible adverse event was seen.

\section{DISCUSSION}

Several proposed mechanisms of trastuzumab resistance included downregulation of HER2, upregulation of expression of PTEN gene or insulin-like growth factor receptor I gene, and also expression of a truncated form of HER2 receptor - p95HER2 (Lu et al, 2001; 
Table 2 Toxic effects of treatment

\begin{tabular}{lcccc}
\hline Toxic effect & Total & Grade I & Grade 2 & Grade 3 \\
\hline Fever & 3 & 2 & 1 & 0 \\
Nausea & 2 & 1 & 2 & 0 \\
Vomiting & 1 & 0 & 1 & 0 \\
Sore mouth & 2 & 2 & 0 & 0 \\
Diarrhoea & 3 & 3 & 0 & 0 \\
Constipation & 1 & 1 & 0 & 0 \\
Fatigue & 5 & 5 & 2 & 1 \\
Muscle pain & 4 & 3 & 3 & 1 \\
Numbness & 1 & 1 & 1 & 1 \\
Sore fingers/toes & 1 & 1 & 0 & 0 \\
Red eye & 1 & 1 & 0 & 0 \\
Rash at injection site & 7 & 6 & 1 & 0 \\
Skin rash & 6 & 5 & 2 & 0 \\
Itchy hands/feet & 1 & 1 & 0 & 0 \\
Headache & 2 & 2 & 1 & \\
\hline
\end{tabular}

Scaltriti et al, 2007). Our pilot study has demonstrated the potential for therapeutic synergy when trastuzumab is combined with GM-CSF in patients with trastuzumab-resistant HER2 + metastatic breast cancer. The addition of GM-CSF to trastuzumab alone provided clinical benefit in $29 \%$ of heavily pretreated patients without causing any grade 4 adverse events.

We tested a different approach to overcoming tumour resistance to trastuzumab: enhancing the effect of trastuzumab through addition of cytokines. One of the antitumour effects of trastuzumab is through the action of innate effector mechanisms, such as ADCC (Drebin et al, 1988; Kim et al, 2002; Spiridon et al, 2002). As a mediator of ADCC, trastuzumab is detected as an abnormality on the HER2 receptor of tumour cells by natural killer (NK) cells, which in turn secrete cytokines and subsequently lead to tumour cell death (Lewis et al, 1993; Sliwkowski et al, 1999). The GM-CSF is commonly used to augment immune response by increases antigen presentation of monocytes and macrocytes, enhances CD20 expression, stimulates the effector function of myeloid cells (i.e., neutrophils, macrophages, NK cells, and dendritic cells), and enhances cell-mediated immunity (Dranoff, 2004; Niitsu et al, 2004; Olivieri et al, 2005). The GM-CSF also mediates ADCC via stimulation of macrophages (Kushner and Cheung, 1989; Erbe et al, 1990; Liesveld et al, 1991; Tarr, 1996), and the ability of GMCSF to increase the production of granulocytes and mononuclear cells, as well as to enhance their cytotoxic activities against tumour cells, is well documented (Kushner and Cheung, 1989; Erbe et al, 1990; Liesveld et al, 1991; Ragnhammar et al, 1992; Tarr, 1996; Yu et al, 1997). The GM-CSF also can affect the migration of granulocytes (Gasson et al, 1984; Barker et al, 1991), resulting in their increased accumulation at tumour sites (Tseng et al, 1999).

Currently, GM-CSF is most often used in cancer treatment as a stimulant of leukocyte production to protect against infection (Jones et al, 1996; Beveridge and Miller, 1998). However, as
GM-CSF can augment immune effector cell functions (Kushner and Cheung, 1989; Erbe et al, 1990; Liesveld et al, 1991; Tarr, 1996), it also may enhance the therapeutic effect of monoclonal antibodies, such as trastuzumab.

Several experimental and clinical studies have demonstrated the antineoplastic effects of GM-CSF alone or in combination with cytokines and/or monoclonal antibodies (Ragnhammar, 1996). The GM-CSF has been shown to enhance anti- $\mathrm{G}_{\mathrm{D} 2}$-mediated ADCC by granulocytes in disease-free subjects and in patients with neuroblastoma (Yu et al, 1997; Batova et al, 1999). A recent pilot trial found that continuous, low-dose GM-CSF had substantial activity (objective response rate 37\%) in heavily pretreated patients with either metastatic breast cancer or female genital tract cancer (Kurbacher et al, 2005). Enhancement of ADCC of human peripheral blood mononuclear cells by GM-CSF has been described (Grabstein et al, 1986; Thomassen et al, 1989), and GM-CSF in conjunction with monoclonal antibodies has been used in clinical trials for the treatment of colorectal carcinoma (Mellstedt et al, 1991; Ragnhammar et al, 1992) and neuroblastoma (Yu et al, 1997). Trial results found that GM-CSF augmented ADCC activity of mononuclear cells and granulocytes against both colorectal cancer cells and neuroblastoma; therapeutic efficacy was demonstrated in these trials (Mellstedt et al, 1991; Ragnhammar et al, 1992; Yu et al, 1997). In this study, we have initially designed to continue the trial in a phase II setting including measurement of the ADCC activities under the influence of GM-CSF and trastuzumab. However, we were not able to accrue patients further to the study due to other competing trials in our institution.

Although targeted therapies, such as combinations of trastuzumab and chemotherapy, have been widely investigated for the treatment of metastatic breast cancer, the role of cytokines, such as GM-CSF, as an immunological stimulant in combination with monoclonal antibodies, has been less well examined. Our pilot study has demonstrated the potential for therapeutic synergy with the combination of GM-CSF and trastuzumab. Administration of GM-CSF is simple, safe, and feasible. Although no disease response was seen in our pilot study, our finding that this simple approach stabilised breast cancer is clinically significant in this setting of metastatic disease. This trastuzumab plus GM-CSF regimen needs further evaluation in combination with chemotherapy or other biological agents in the management of metastatic breast cancer. Further, there is a need to determine whether ADCC activities are measured.

\section{ACKNOWLEDGEMENTS}

We thank Stephanie Deming for her excellent help in developing this manuscript. This research work was supported in part by Bayer (to NTU).

\section{REFERENCES}

Atalay G, Cardoso F, Awada A, Piccart MJ (2003) Novel therapeutic strategies targeting the epidermal growth factor receptor (EGFR) family and its downstream effectors in breast cancer. Ann Oncol 14: 1346-1363 Barker E, Mueller BM, Handgretinger R, Herter M, Yu AL, Reisfeld RA (1991) Effect of a chimeric anti-ganglioside $G_{D 2}$ antibody on cellmediated lysis of human neuroblastoma cells. Cancer Res 51: 144-149

Baselga J, Norton L, Albanell J, Kim YM, Mendelsohn J (1998) Recombinant humanized anti-HER2 antibody (Herceptin) enhances the antitumor activity of paclitaxel and doxorubicin against HER2/neu overexpressing human breast cancer xenografts. Cancer Res 58: 2825-2831

Batova A, Kamps A, Gillies SD, Reisfeld RA, Yu AL (1999) The Ch14.18GM-CSF fusion protein is effective at mediating antibody-dependent cellular cytotoxicity and complement-dependent cytotoxicity in vitro. Clin Cancer Res 5: 4259-4263

Beveridge RA, Miller JA, Kales AN, Binder RA, Robert NJ, Harvey JH, Windsor K, Gore I, Cantrell J, Thompson KA, Taylor WR, Barnes HM, Schiff SA, Shields JA, Cambareri RJ, Butler TP, Meister RJ, Feigert JM, Norgard MJ, Moraes MA, Helvie WW, Patton GA, Mundy LJ, Henry D, Mason B, Staddon A, Ford P, Katcher D, Houck W, Major WB, Gemma NW, Kay G, Priest E, Sowroy P, Bank B, Leibach S, Reisel H, Grad G, Warren RD, Ueno WM, Smith LF, Dobrzynski RF, Sheridan MJ (1998) A comparison of efficacy of sargramostim (yeast-derived RhuGM-CSF) and filgrastim (bacteria-derived RhuG-CSF) in the therapeutic setting of chemotherapy-induced myelosuppression. Cancer Invest 16: 366-373 
Cobleigh MA, Vogel CL, Tripathy D, Robert NJ, Scholl S, Fehrenbacher L Wolter JM, Paton V, Shak S, Lieberman G, Slamon DJ (1999) Multinational study of the efficacy and safety of humanized anti-HER2 monoclonal antibody in women who have HER-2 overexpressing metastatic breast cancer that has progressed after chemotherapy for metastatic disease. J Clin Oncol 17: 2639-2648

Dranoff G (2004) Cytokines in cancer pathogenesis and cancer therapy. Nat Rev Cancer 4: 11-22

Drebin JA, Link VC, Greene MI (1988) Monoclonal antibodies specific for the neu oncogene product directly mediate anti-tumor effects in vivo. Oncogene 2: 387-394

Erbe DV, Collins J, Shen L, Graxiano RF, Fanger MW (1990) The effect of cytokines on the expression and function of Fc receptors for IgG on human myeloid cells. Mol Immunol 27: 57-67

Esteva FJ, Valero V, Booser D, Guerra LT, Murray JL, Pusztai L, Cristofanilli M, Arun B, Esmaeli B, Fritsche HA, Sneige N, Smith TL, Hortobagyi GN (2002) Phase II study of weekly docetaxel and trastuzumab for patients with HER-2overexpressing metastatic breast cancer. J Clin Oncol 20: 1800-1808

Gasson JC, Weisbart RH, Kaufman SE, Clark SC, Hewick RM, Wong GG, Golde DW (1984) Purified human granulocyte-macrophage colony stimulating factor: direct action on neutrophils. Science 226: 1339-1342

Grabstein KH, Urdal DL, Tushinski RJ, Mochizuki DY, Price VL, Cantrell MA, Gillis S, Conlon PJ (1986) Induction of macrophage tumoricidal activity by granulocyte-macrophage colony-stimulating factor. Science 232: $506-508$

Jones SE, Schottstaedt MW, Duncan LA, Kirby RL, Good RH, Mennel RG, George TK, Snyder DA, Watkins DL, Denham CA, Hoyes FA, Rubin AS (1996) Randomized double-blind prospective trial to evaluate the effects of sargramostim versus placebo in a moderate-dose fluorouracil, doxorubicin, and cyclophosphamide adjuvant chemotherapy program for stage II and III breast cancer. J Clin Oncol 14: 2976-2983

Kim KM, Shin EY, Moon JH, Heo TH, Lee JY, Chung Y, Lee YJ, Cho HM, Shin SU, Kang CY (2002) Both the epitope specificity and isotype are important in the antitumor effect of monoclonal antibodies against Her-2/neu antigen. Int J Cancer 102: 428-434

Kurbacher CM, Kurbacher JA, Cramer EM, Rhiem K, Mallman PK, Reichelt R, Reinhold U, Stier U, Cree IA (2005) Continuous low-dose GM-CSF as salvage therapy in refractory recurrent breast or female genital tract carcinoma. Oncology 19(4 suppl 2): 23-26

Kushner BH, Cheung NK (1989) GM-CSF enhances 3F8 monoclonal antibody-dependent cellular cytotoxicity against human melanoma and neuroblastoma. Blood 73: 1936-1941

Lewis GD, Figari I, Fendly B, Wong WL, Carter P, Gorman C, Shepard HM (1993) Differential responses of human tumor cell lines to anti-p185 ${ }^{\text {HER2 }}$ monoclonal antibodies. Cancer Immunol Immunother 37: 255-263

Liesveld JL, Frediani D, Winslow JM, Duerst RE, Abboud CN (1991) Cytokine effects and role of adhesive proteins and Fc receptors in human macrophage-mediated antibody dependent cellular cytotoxicity. J Cell Biochem 45: $381-390$

Lu Y, Zi X, Zhao Y, Mascarenhas D, Pollak M (2001) Insulin-like growth factor-I receptor signaling and resistance to trastuzumab (Herceptin). J Natl Cancer Inst 93: 1852-1857

Marty M, Cognetti F, Maraninchi D, Snyder R, Mauriac L, Tubiana-Hulin M, Chan S, Grimes D, Antón A, Lluch A, Kennedy J, O'Byrne K, Conte P, Green M, Ward C, Mayne K, Extra JM (2005) Randomized phase II trial of the efficacy and safety of trastuzumab combined with docetaxel in patients with human epidermal growth factor receptor 2-positive metastatic breast cancer administered as first-line treatment: the M77001 study group. J Clin Oncol 23: 4265-4274

Mellstedt H, Frödin JE, Ragnhammar P, Masucci G, Ljungberg A, Hjelm AL, Fagerberg J, Lindemalm C, Osterborg A, Wersäll P (1991) Therapy of colorectal carcinoma with monoclonal antibodies (Mab17-1A) alone and in combination with granulocyte monocyte-colony stimulating factor (GM-CSF). Acta Oncol 30: 923-931

Nahta R, Hung MC, Esteva FJ (2004) The HER-2-targeting antibodies trastuzumab and pertuzumab synergistically inhibit the survival of breast cancer cells. Cancer Res 64: 2343-2346

Niitsu N, Hayama M, Okamoto M, Khori M, Higashihara M, Tamaru J, Hirano M (2004) Phase I study of rituximab-CHOP in combination with GMCSF in patients with follicular lymphoma. Clin Cancer Res 10: 4077-4082

Olivieri A, Lucesole M, Capelli D, Gini G, Montanari M, Candela M, Troiani E, Scortechini I, Poloni A, Leoni P (2005) A new schedule of CHOP/ rituximab plus granulocyte-macrophage colony-stimulating factor is an effective rescue for patients with aggressive lymphoma failing autologous stem cell transplantation. Biol Blood Marrow Transplant 11: 627-636
Pegram M, Hsu S, Lewis G, Pietras R, Beryt M, Sliwkowski M, Coombs D, Baly D, Kabbinavar F, Slamon D (1999) Inhibitory effects of combinations of HER-2/neu antibody and chemotherapeutic agents used for treatment of human breast cancers. Oncogene 18: 2241-2251

Pietras RJ, Arboleda J, Reese DM, Wongvipat N, Pegram MD, Ramos L, Gorman CM, Parker MG, Sliwkowski MX, Slamon DJ (1995) HER-2 tyrosine kinase pathway targets estrogen receptor and promotes hormone-independent growth in human breast cancer cells. Oncogene 10: 2435-2446

Press MF, Pike MC, Chazin VR, Hung G, Udove JA, Markowicz M, Danyluk J, Godolphin W, Sliwkowski M, Akita R, Paterson MC, Slamon DJ (1993) HER-2/neu expression in node negative breast cancer: direct tissue quantitation by computerized image analysis and association of overexpression with increased risk of recurrent disease. Cancer Res 53: 4960 - 4970

Ragnhammar P (1996) Anti-tumoral effect of GM-CSF with or without cytokines and monoclonal antibodies in solid tumors. Med Oncol 13: 167-176

Ragnhammar P, Masucci G, Frödin JE, Hjelm AL, Mellstedt H (1992) Cytotoxic functions of blood mononuclear cells in patients with colorectal carcinoma treated with $\mathrm{mAb} 17-1 \mathrm{~A}$ and granulocyte/macrophage-colony stimulating factor. Cancer Immunol Immunother 35: 158-164

Ravdin PM, Chamness GC (1995) The c-erbB-2 proto-oncogene as a prognostic and predictive marker in breast cancer: a paradigm for the development of other macromolecular markers-a review. Gene 159: 19-27

Repka T, Chiorean EG, Gay J, Herwig KE, Kohl VK, Yee D, Miller JS (2003) Trastuzumab and interleukin-2 in HER2-positive metastatic breast cancer: a pilot study. Clin Cancer Res 9: 2440-2446

Scaltriti M, Rojo F, Ocaña A, Anido J, Guzman M, Cortes J, Di Cosimo S, Matias-Guiu X, Ramon y Cajal S, Arribas J, Baselga J (2007) Expression of p95HER2, a truncated form of the HER2 receptor, and response to anti-HER2 therapies in breast cancer. J Natl Cancer Inst 99: 628-638

Seidman AD, Fornier M, Esteva FJ, Tan L, Kaptain S, Bach A, Panageas KS, Arroyo C, Valero V, Currie V, Gilewski T, Theodoulou M, Moynahan ME, Moasser M, Sklarin N, Dickler M, D'Andrea G, Cristofanilli M, Rivera E, Hortobagyi GN, Norton L, Hudis CA (2001) Weekly trastuzumab and paclitaxel therapy for metastatic breast cancer with analysis of efficacy by HER2 immunophenotype and gene amplification. J Clin Oncol 19: 2587-2595

Seshadri R, Firgaira FA, Horsfall DJ, McCaul K, Setlur V, Kitchen P (1993) Clinical significance of HER-2/neu oncogene amplification in primary breast cancer. J Clin Oncol 11: 1936-1942

Sjögren S, Inganäs M, Lindgren A, Homberg L, Bergh J (1998) Prognostic and predictive value of c-erbB-2 overexpression in primary breast cancer, alone and in combination with other prognostic markers. J Clin Oncol 16: $462-469$

Slamon DJ, Clark GM, Wong SG, Levin WJ, Ullrich A, McGuire WL (1987) Human breast cancer: correlation of relapse and survival with amplification of the HER-2/neu oncogene. Science 235: 177-182

Slamon DJ, Leyland-Jones B, Shak S, Fuchs H, Paton V, Bajamonde A, Fleming T, Eiermann W, Wolter J, Pegram M, Baselga J, Norton L (2001) Use of chemotherapy plus a monoclonal antibody against HER2 for metastatic breast cancer that overexpresses HER2. N Engl J Med 344: 783-792

Sliwkowski MX, Lofgren JA, Lewis GD, Hotaling TE, Fendly BM, Fox JA (1999) Nonclinical studies addressing the mechanism of action of trastuzumab (Herceptin). Semin Oncol 26(4 suppl 12): 60-70

Sondel PM, Hank JA (2001) Antibody-directed, effector cell-mediated tumor destruction. Hematol Oncol Clin North Am 15: 703-721

Spiridon CI, Ghetie MA, Uhr J, Marches R, Li JL, Shen GL, Vitetta ES (2002) Targeting multiple Her-2 epitopes with monoclonal antibodies results in improved antigrowth activity of a human breast cancer cell line in vitro and in vivo. Clin Cancer Res 8: $1720-1730$

Stein S, DeMichele A, Domchek S, Fox K (2004) Gemcitabine and trastuzumab combinations for patients with metastatic breast cancer overexpressing HER2/neu. Clin Breast Cancer 4(suppl 3): S117-S120

Tarr PE (1996) Granulocyte-macrophage colony-stimulating fctor and the immune system. Med Oncol 13: 133-140

Thomassen MJ, Barna BP, Rankin D, Wiedemann HP, Ahmad M (1989) Differential effect of recombinant granulocyte macrophage colonystimulating factor on human monocytes and alveolar macrophages. Cancer Res 49: 4086-4089

Tseng SH, Hsieh CL, Lin SM, Hwang LH (1999) Regression of orthotopic brain tumors by cytokine-assisted tumor vaccines primed in the brain. Cancer Gene Ther 6: 302-312

Yu AL, Batova A, Alvarado C, Rao VJ, Castleberry RP (1997) Usefulness of a chimeric anti-GD2 (ch14.18) and GM-CSF for refractory neuroblastoma: a POG phase II study [abstract]. Proc Am Soc Clin Oncol 16: 513a. A1846 